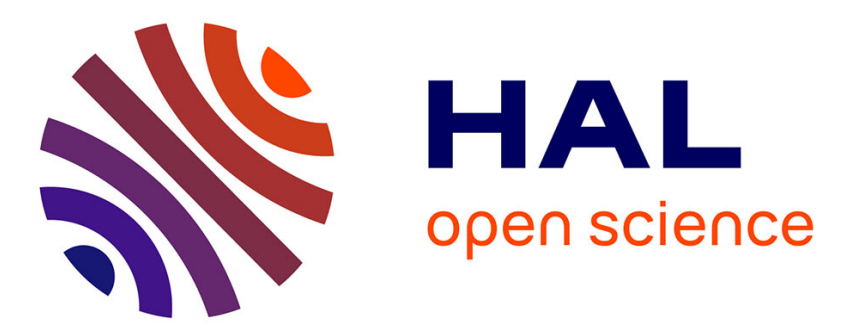

\title{
Two-dimensional gel proteome analysis of honeybee, Apis mellifera, worker red-eye pupa hemolymph
}

Tomas Erban, Dagmar Petrova, Karel Harant, Petr Jedelsky, Dalibor Titera

\section{To cite this version:}

Tomas Erban, Dagmar Petrova, Karel Harant, Petr Jedelsky, Dalibor Titera. Two-dimensional gel proteome analysis of honeybee, Apis mellifera, worker red-eye pupa hemolymph. Apidologie, 2013, 45 (1), pp.53-72. 10.1007/s13592-013-0230-9 . hal-01234707

\section{HAL Id: hal-01234707 https://hal.science/hal-01234707}

Submitted on 27 Nov 2015

HAL is a multi-disciplinary open access archive for the deposit and dissemination of scientific research documents, whether they are published or not. The documents may come from teaching and research institutions in France or abroad, or from public or private research centers.
L'archive ouverte pluridisciplinaire HAL, est destinée au dépôt et à la diffusion de documents scientifiques de niveau recherche, publiés ou non, émanant des établissements d'enseignement et de recherche français ou étrangers, des laboratoires publics ou privés. 


\title{
Two-dimensional gel proteome analysis of honeybee, Apis mellifera, worker red-eye pupa hemolymph
}

\author{
Tomas Erban ${ }^{1}$, Dagmar Petrova ${ }^{1}$, Karel Harant ${ }^{4}$, Petr L. Jedelsky ${ }^{3,4,5}$, \\ Dalibor TITERA ${ }^{2,6}$ \\ ${ }^{1}$ Department of Pest Control of Stored Products and Food Safety, Laboratory of Proteomics, Crop Research \\ Institute, Drnovska 507/73, Prague 6-Ruzyne, CZ16106, Czech Republic \\ ${ }^{2}$ Bee Research Institute at Dol, Libcice nad Vltavou, Czech Republic \\ ${ }^{3}$ Department of Parasitology, Faculty of Science, Charles University in Prague, Prague, Czech Republic \\ ${ }^{4}$ Service Laboratories of the Biology Section, Laboratory of Mass Spectrometry, Faculty of Science, Charles \\ University in Prague, Prague, Czech Republic \\ ${ }^{5}$ Department of Cell Biology, Faculty of Science, Charles University in Prague, Prague, Czech Republic \\ ${ }^{6}$ Department of Zoology and Fisheries, Faculty of Agrobiology, Food and Natural Resources, Czech University of \\ Life Sciences Prague, Prague 6-Suchdol, Czech Republic
}

Received 1 January 2013 - Revised 28 June 2013 - Accepted 17 July 2013

\begin{abstract}
Apis mellifera Linnaeus is a holometabolous insect that undergoes complete metamorphosis in its nonfeeding pupal stage before transitioning to the adult stage. Its pupal stages are classifiable by the unique color pigmentation of its compound eyes and thorax; notably, there is a red-eye stage involving an unpigmented body that has a relatively short duration and is easy to recognize. The aim of the current study was to create a proteomic reference map of the worker red-eye pupa hemolymph. Hemolymph was collected from dorsal vessels using glass capillary tubes and was examined using pI 3-10 two-dimensional gel electrophoresis (2DE; 10 and $14 \%$ ) and matrix-assisted laser desorption/ionization (MALDI) time-of-flight (TOF)/TOF protein identification. This experimental approach allowed us to identify 129 different proteins organized into orthologous groups. Overall, the predominant category was posttranslational modifications, protein turnover and chaperones ( $23.3 \%$ of the identified proteins). In addition, we identified proteins in the non-orthologous groups of olfaction ( $2.3 \%$ of the identified proteins) and storage hexamerins ( $3.1 \%$ of the identified proteins). Quantitatively, the major protein isoforms that were accurately identified via $10 \%$ 2DE were four forms of storage hexamerin: the $110,70 \mathrm{a}, 70 \mathrm{~b}$, and $70 \mathrm{c}$ forms. The most abundant enzymes identified were short-chain dehydrogenases/reductases with pivotal developmental roles in ecdysteroidogenesis and a sigma class glutathione-S-transferase that most likely serves as a major protectant against the by-products of oxidative stress. Many of the identified proteins are known to be involved in the mechanisms of metamorphosis. All of the identified proteins are useful as markers for future comparative physiological and developmental studies.
\end{abstract}

\section{Honeybee / pupa / hemolymph / metamorphosis / proteome / hexamerin}

\section{INTRODUCTION}

The sequenced and annotated genome (Honeybee Genome Sequencing Consortium 2006) of the

Corresponding author: T. Erban, arachnid@centrum.cz

Manuscript editor: Klaus Hartfelder honeybee, Apis mellifera Linnaeus, allows for large-scale mass spectrometry (MS)-based proteomic studies to be performed on this species. Similar to vertebrate blood, the proteins in insect hemolymph provide important information on physiology and the immune system and reflect the health of the organism (Levy et al. 2004; Chan et al. 2006; Randolt et al. 2008; Bogaerts et al. 2009). Insect 
hemolymph is a body fluid that is mainly composed of water, inorganic salts, carbohydrates (mainly trehalose), proteins, hormones, lipids, free amino acids, and macrophage-like cells (hemocytes). The hemolymph mediates chemical exchanges between tissues and organs and serves as a water reserve (Leta et al. 1996; Lavine and Strand 2002; Hrassnigg et al. 2003; Chan et al. 2006; Burmester and Hankeln 2007). Because honeybees are social insects and the protein composition of the hemolymph varies between developmental stages, hemolymph proteins can be used to investigate caste differences and development (Danty et al. 1998; Chan et al. 2006; Chan and Foster 2008; Bogaerts et al. 2009; Erban et al. 2013). Proteomic studies investigating the role of hemolymph proteins in honeybee physiology remain rare. Honeybee hemolymph has been previously examined using one-dimensional gel electrophoresis (1DE) in adults and/or larvae (Chan et al. 2006; Randolt et al. 2008; Chan and Foster 2008), while two-dimensional gel electrophoresis (2DE) and a gel-free system (2DLC) have been used to evaluate summer adults (Bogaerts et al. 2009), and 2DE was used to study summer de-queened adults (Cardoen et al. 2011), worker and queen larvae (Li et al. 2010b) and winter workers (Erban et al. 2013). N-terminal sequencing was used with 1DE to identify the hemolymph hexamerins (Danty et al. 1998). However, the pupal hemolymph proteome has not yet been studied with MS or 2DE proteomic techniques.

The pupal stage is a nonfeeding, immobile, reconstruction stage when larval tissues are broken down and rebuilt. The honeybee begins its pupal stage when the larva is sealed into its cell after the final molting (Gullan and Cranston 2005). Although there are caste differences in the duration and size of the pupal stage (Rembold et al. 1980), honeybee pupal stages are classifiable by the color pigmentations of their compound eyes and thorax. The distinguished pupal eye colorations are white, pink, red, and brown (Duay et al. 2003). The red-eye stage is sometimes omitted when describing the pupal stage in the literature (Michelette and Soares 1993; Barchuk et al. 2002; Piulachs et al. 2003), and a dark pink (Michelette and Soares 1993) or red/brown (Rembold et al. 1980) color is instead recognized and denoted. However, the pink/red compound eye stage is characterized by a nonpigmented (unmelanized) body (Rembold et al. 1980; Michelette and Soares 1993; Barchuk et al. 2002; Piulachs et al. 2003; Duay et al. 2003). The relatively easy recognition and short duration of the red-eye stage makes it useful for studying the physiological and developmental oddities that can be caused by entomopathogens, such as viruses, bacteria, Nosema, or the hemolymph-sucking mite, Varroa.

In this study, we aimed to establish a $2 \mathrm{DE}$ map of the A. mellifera worker red-eye pupal stage. We present an overview of the proteins present in the hemolymph to offer insight into the red-eye pupal developmental stage. The resulting map will be useful for future studies on pupal development or pupal diseases.

\section{MATERIALS AND METHODS}

\subsection{Biological samples}

The worker red-eye pupas used in this study were collected from an A. mellifera carnica colony at the Bee Research Institute at Dol in the Czech Republic. A monitored honeybee colony was selected. Hemolymph was collected from the dorsal vessels after puncture of the abdominal intersegmental membrane between the fourth and fifth tergites. Approximately $2 \mu \mathrm{L}$ of transparent hemolymph was collected from each individual. The hemolymph was transferred from the glass capillary tube to a microcentrifuge tube. The collected samples were stored on ice during collection.

\subsection{Two-dimensional gel electrophoresis}

A total of $20 \mu \mathrm{L}$ of pooled hemolymph from eight to ten individuals was used for each 2DE run. We did not process the hemolymph before analysis and the samples were directly used for isoelectrofocusing (IEF). IEF was performed using an Ettan IPG Phor 3 instrument (GE Healthcare). IEF separation was performed in $13 \mathrm{~cm}$ ceramic strip holders using Immobiline ${ }^{\mathrm{TM}}$ DryStrips with a pH range of 3-10 (Cat. No. 17-6001-14, GE Healthcare). DeStreak ${ }^{\mathrm{TM}}$ rehydration solution (Cat. No. 18-1168-31; GE Healthcare), containing $0.5 \%$ IPG buffer (Cat. No. 17-6000-87; GE Healthcare), was used for active rehydration. The separation procedure (total $\mathrm{Vh}$ 32600, duration $19 \mathrm{~h}$ ) was as follows: (1) step, $30 \mathrm{~V}, 10 \mathrm{~h}$ 
(active rehydration); (2) step $500 \mathrm{~V}, 500 \mathrm{Vh}$; (3) Grad 1,000 V, $800 \mathrm{Vh}$; (4) Grad 6,000 V, 15,000 Vh; and (5) step $6,000 \mathrm{~V}, 16,000 \mathrm{Vh}$. Immediately following IEF, the strips were equilibrated for $15 \mathrm{~min}$ in equilibration buffer containing dithiothreitol (DTT; Cat. No. 43817, SigmaAldrich) and for $15 \mathrm{~min}$ in buffer containing iodoacetamide (IAA; Cat. No. 57670, Sigma-Aldrich). The equilibrated strips were placed on a 14 or $10 \%$ sodium dodecyl sulfate polyacrylamide gel (SDS-PAGE) and fixed with $1 \%$ agarose (Cat. No. A7431, SigmaAldrich). The gel was prepared according to the manufacturer's instructions from 37.5:1 acrylamide/bisacrylamide solution (Cat. No. A3699, Sigma-Aldrich). Electrophoresis was carried out under cooling at a constant voltage of $77 \mathrm{~V}$ for $30 \mathrm{~min}$ in an SE 600 Ruby electrophoresis instrument (GE Healthcare), after which the proteins were separated at a constant voltage of $300 \mathrm{~V}$.

After electrophoresis, the gels were processed using the Coomassie staining method. The gels were fixed in fixing solution ( $40 \%$ LC-MS grade methanol, $10 \%$ ice acetic acid, and $50 \%$ nanopure water) overnight. After removing the fixing solution, the gels were stained using $0.02 \%$ PhastGel $^{\mathrm{TM}}$ Blue R (Coomassie R 350 stain; Cat. No. 17-0518-01, GE Healthcare). Unused fixing solution was used for destaining. Finally, the results were visualized with the G:BOX documentation system (Syngene) in automatic capture mode.

\subsection{MALDI TOF/TOF sample preparation}

For matrix-assisted laser desorption/ionization (MALDI) time-of-flight (TOF)/TOF identification, spots ( 0.5-1 mm inner diameter) were manually selected from the Coomassie-stained gels and placed into a $0.6 \mathrm{~mL}$ microtube. Spots were covered with $100 \mu \mathrm{L} 50-\mathrm{mM}$ ammonium bicarbonate (ABC) buffer in $50 \%$ acetonitrile (ACN) with $50 \mathrm{mM}$ DTT. All samples were subjected to sonication in an ultrasonic cleaning bath for $5 \mathrm{~min}$. After $15 \mathrm{~min}$, the supernatant was discarded and the gel was covered with $100 \mu \mathrm{L}$ of $50 \mathrm{mM} \mathrm{ABC} / 50 \% \mathrm{ACN}$ with $50 \mathrm{mM}$ IAA and sonicated for $5 \mathrm{~min}$. After $25 \mathrm{~min}$, the supernatant was discarded and exchanged for $100 \mu \mathrm{L}$ $50 \mathrm{mM} \mathrm{ABC} / 50 \% \mathrm{ACN}$ with $50 \mathrm{mM}$ DTT and sonicated for $5 \mathrm{~min}$ to remove any excess IAA. The supernatant was discarded and the samples were sonicated for $5 \mathrm{~min}$ in $100 \mu \mathrm{L}$ of HPLC/MS-grade water. The water was discarded and samples were sonicated for another $5 \mathrm{~min}$ in $100 \mu \mathrm{L}$ of $\mathrm{ACN}$. The ACN was discarded, and the microtubes with the samples were left open for a couple of minutes to allow the rest of the ACN to evaporate. Then, $5 \mathrm{ng}$ of trypsin (Cat. No. v5111, Promega) in $10 \mu \mathrm{L}$ of $50 \mathrm{mM} \mathrm{ABC}$ were added to the gel. The samples were incubated at $37{ }^{\circ} \mathrm{C}$ overnight. Trifluoroacetic acid (TFA) and $\mathrm{ACN}$ were added for a final concentration of $1 \%$ TFA and $30 \%$ ACN. The samples were sonicated for $10 \mathrm{~min}$, and a $0.5 \mu \mathrm{L}$ drop was transferred onto MALDI targets and allowed to dry. The dried droplets were covered with a $0.5 \mu \mathrm{L}$ drop of $\alpha$-cyano-4hydroxycinnamic acid (Cat. No. 70990, Sigma-Aldrich) solution $(10 \mathrm{mg} / \mathrm{mL}$ in $50 \% \mathrm{ACN})$ and allowed to dry.

\subsection{MALDI TOF/TOF protein identification}

The MS spectra were acquired in the range of 700$4,000 \mathrm{~m} / \mathrm{z}$ using a 4800 Plus MALDI TOF/TOF analyzer (Applied Biosystems/MDS Sciex) equipped with an Nd:YAG laser $(355 \mathrm{~nm}$, firing rate of $200 \mathrm{~Hz}$ ). Ten strongest precursors were selected for MS/MS analysis. Peak lists were generated from the MS spectra using a 4000 Series Explorer V 3.5.3 (AB Sciex) without smoothing. Peaks with a local signal-to-noise ratio greater than 5 were selected automatically. The spectra were then subjected to searches against the nonredundant National Center for Biotechnology Information (NCBI) 20130221 database $(23,214,025$ sequences; 7,977,717,942 residues) using MASCOT 2.2 (Matrix Science). The database search criteria were as follows: enzyme, trypsin; taxonomy, Insecta (749851 sequences); fixed modification, carbamidomethylation (C); variable modifications, deamidated (NQ) and methionine oxidation $(\mathrm{M})$; protein mass, unrestricted; peptide mass tolerance, $\pm 125 \mathrm{ppm}$; fragment mass tolerance, $\pm 0.3 \mathrm{Da}$; and one missed cleavage allowed. Hits that were scored and a $p<0.05$ was considered significant. The protein score was $-10 * \log (p)$, where $p$ is the probability that the observed match is a random event. Protein scores were derived from ion scores as a nonprobabilistic basis for ranking protein hits.

\subsection{Protein classification}

For protein classification, the considered results were entered into the NCBI protein (http:// www.ncbi.nlm.nih.gov/protein/), UniProt (http:// www.uniprot.org/), eggNOG (http://eggnog.embl.de/), and STRING (http://string-db.org/) databases to find 
clusters of predicted orthologs. The proteins were assigned based on function according to the combined search results (obtained KOGs, COGs, or NOGs) and assembled into orthologous groups based on NCBI COGs (http:// www.ncbi.nlm.nih.gov/COG/). Pie charts were generated using OriginPro 8 software (v8.0891, OriginLab).

\section{RESULTS}

A 2DE proteomic profile of honeybee worker redeye pupa hemolymph was obtained for the first time. Significant MALDI TOF/TOF results were protein scores greater than 71 . Representative images of the 2DE Coomassie-stained 14 and $10 \%$ SDS-PAGE pI 3-10 IEF gels are presented in Figures 1A,B and 2, respectively; see the Electronic supplementary material (ESM) Tables $1 \mathrm{AB}$ and $2 \mathrm{AB}$ for the list of identified proteins with details of identification and characterization. The patterns obtained from technical replicates of the 2DE gels were almost identical, and we observed distinctive separation of proteins of higher molecular weights (such as hexamerins), which was due to their high content in the hemolymph sample. The application of $10 \%$ SDSPAGE separation in the second dimension of 2DE greatly improved the separation of the higher molecular mass protein spots, and we were able to easily distinguish four hexamerin forms in the hemolymph. The 10 and $14 \%$ 2DE assays allowed for significance to be assigned to 277 and 109 protein spots, respectively. In total, 129 different proteins were identified. The proteins were grouped and functionally categorized into 20 categories (Figure 3). Overall, the most abundant category was posttranslational modification, protein turnover, and chaperones $(23.3 \%)$. However, some proteins were not found to be members of orthologous groups such as three members of the olfaction $(2.3 \%)$ and four members of the hexamerin-storage protein $(3.1 \%)$ categories. In addition, some proteins belonged to more than one category and were assigned to a multiple function ( $4.7 \%$ ) category. Many identified proteins were previously identified in hemolymph of adult summer workers (Bogaerts et al. 2009), winter adult workers (Erban et al. 2013), and larvae (Chan et al. 2006; Randolt et al. 2008; Chan and Foster 2008). Herein, the most important proteins and protein groups are discussed.

\section{DISCUSSION}

\subsection{Hexamerin-storage protein}

The hexamerins were found to be the most abundant hemolymph proteins. Hexamerins are highly expressed because they are principally storage proteins that serve as a source of energy and amino acids in nonfeeding periods and when the demand for amino acids is high. Hexamerins are synthesized mainly by the fat body during larval development and belong to a family of proteins that includes hemocyanins, which lack an oxygen transport function and prophenoloxidases. Hexamerins may also function as arylphorin-receptor proteins and juvenile hormone (JH)-binding proteins (Burmester et al. 1998; Burmester 2002; Martins et al. 2008, 2010). In the 2DE analyses, we successfully identified protein products that were expressed by all four hexamerin genes identified in the honeybee genome: Hex70a, Hex70b, Hex70c, and Hex110 (Martins et al. 2010). The 2DE profile revealed the distribution of hexamerin expression in the hemolymph, indicating that in the red-eye pupa these proteins rank as follows: hexamerin 110 (BAI82214), the most abundant; 70a (NP_001104234; ABR45904) and 70b (NP_001011600), which are present in moderate amounts; and 70c (ABR45905), the least abundant. Notably, four spots corresponding to a high molecular weight hexamerin $70 \mathrm{a}$ were identified in all of the 2DE gels that were analyzed. The presence of hexamerin spots smaller than the theoretical MW (70-110 kDa) may be due to the post-translational cleavage of hexamerin (Burmester and Scheller 1999). Spots smaller than the theoretical MW were identified in 2DE analyses of both the hemocytes and the fat body of Sarcophaga bullata (Masova et al. 2010). Hemocyte localization to the hemolymph was suggested in winter honeybee hemolymph (Erban et al. 2013).

Studies on hexamerin expression conducted in different developmental stages, castes, and tissues have revealed distinct structural organizations and expression patterns, suggesting that hexamerins have specialized functions in honey bee physiology (Cunha et al. 2005; Martins et al. 2010). Hexamerin 110 , which has different isoforms with sizes of $\sim 110$ 

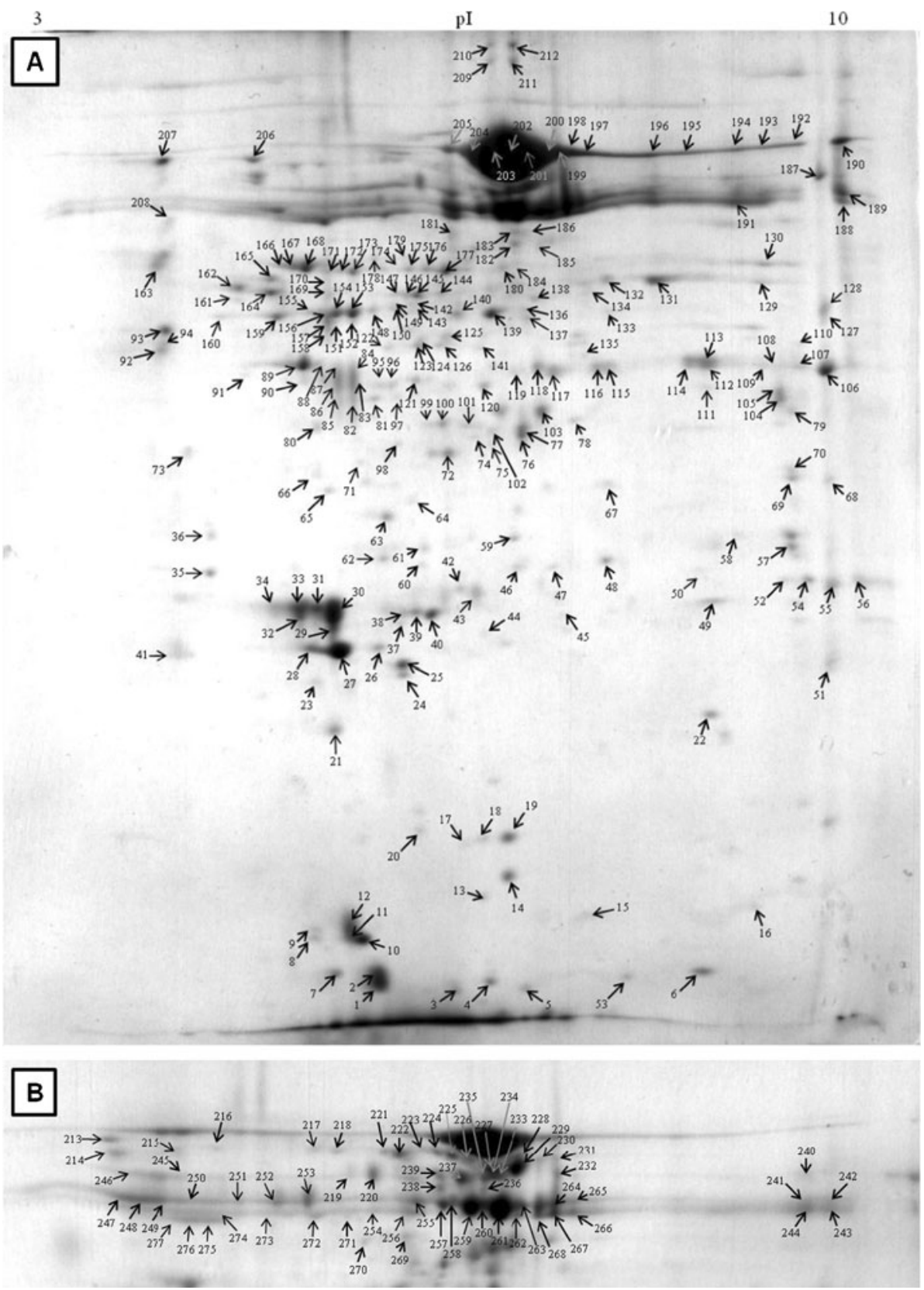

Figure 1 Proteome map of the A. mellifera worker red-eye pupa hemolymph. A 2DE separation was performed on IPG gel strips (pI 3-10) followed by $14 \%$ SDS-PAGE. Protein spots identified in an entire 2DE gel (A) and protein spots identified in a region of hexamerins with better separation $(\mathbf{B})$. See the ESM Table 1AB for the list of identified proteins. See the ESM Figure 1 for the figures lacking assigned identified spots (four repeats) 


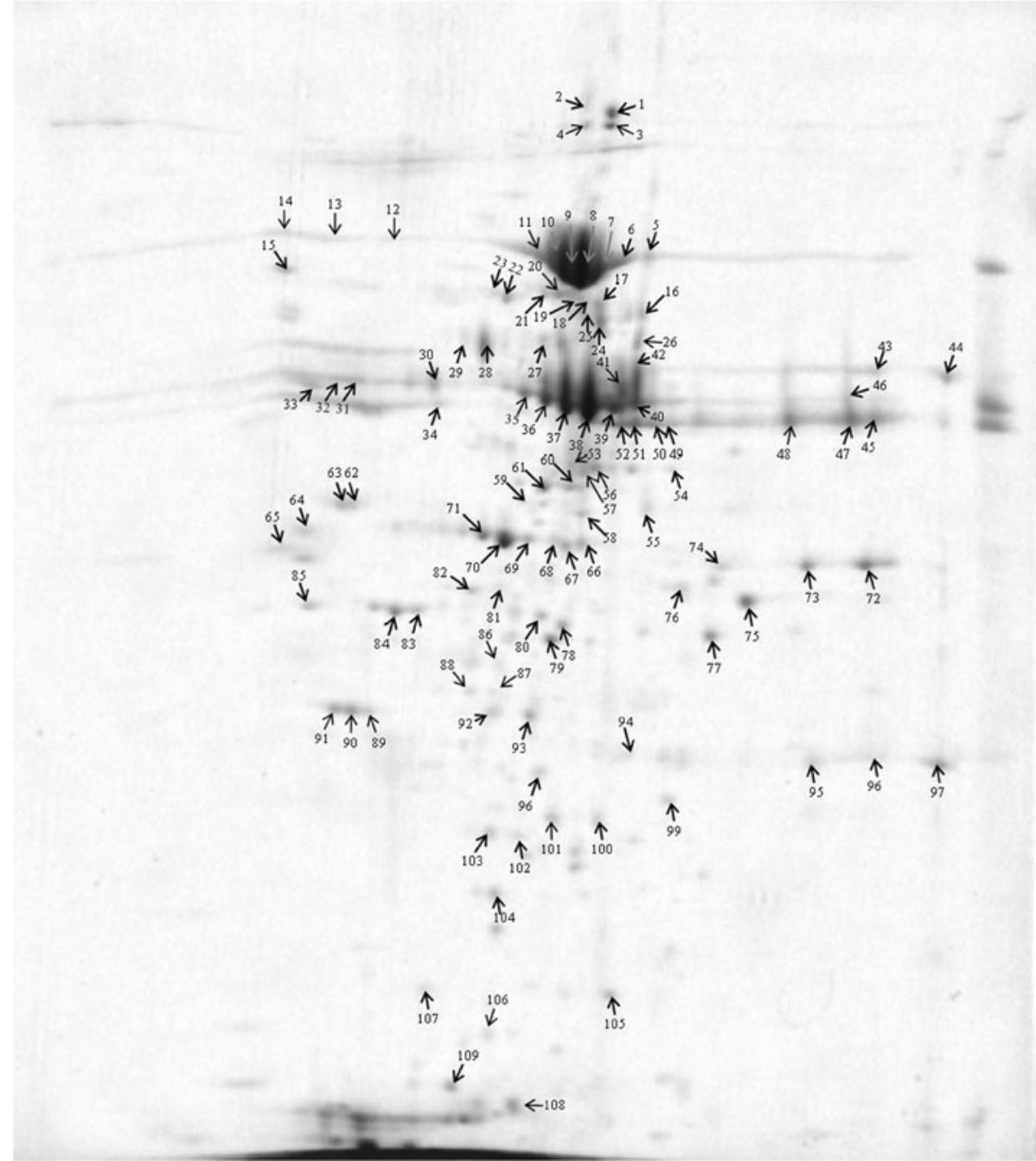

Figure 2 Proteome map of A. mellifera worker red-eye pupa hemolymph. A 2DE separation was performed on IPG gel strips (pI 3-10) followed by $10 \%$ SDS-PAGE. See the ESM Table 2AB for the list of identified proteins. See ESM Figure 2 for the figures lacking assigned identified spots (two repeats)

and $\sim 80 \mathrm{kDa}$, decreases steadily in the hemolymph from the larval through the pupal stage, and its decrease is associated with cuticle pigmentation. The protein nearly disappears before the end of metamorphosis (Danty et al. 1998; Cunha et al. 2005; Bitondi et al. 2006). Hexamerins 70b, 70c, and $70 \mathrm{a}$ are present in the pupal hemolymph continuously until emergence. However, 70c and
$70 \mathrm{~b}$ disappear in drones before the transition to the adult stage, whereas $70 \mathrm{c}$ and $70 \mathrm{~b}$ disappear from

Figure 3 Pie chart representing the identified functional categories of the of the A. mellifera worker redeye pupa hemolymph proteins; 129 different proteins are included 


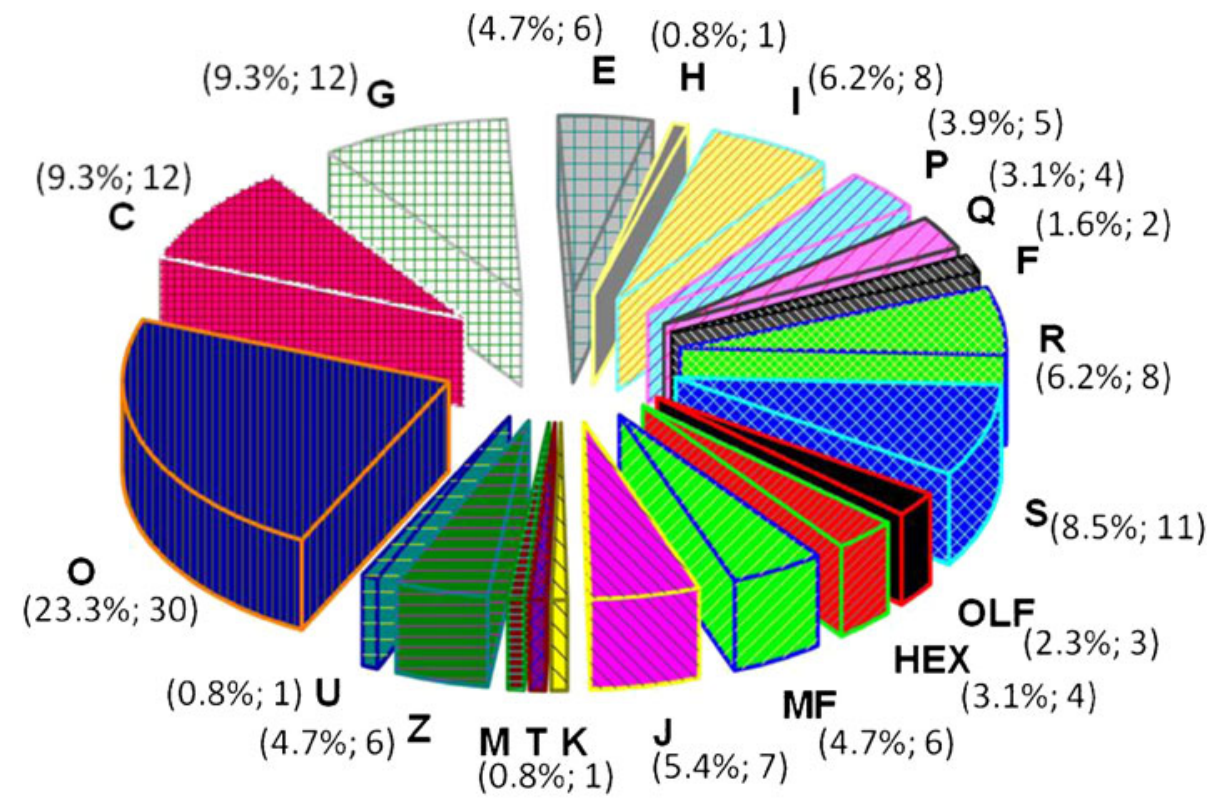

\footnotetext{
Others

OLF - Olfaction

HEX - Hexamerin - storage protein

MF - Multiple function

Information storage and processing

I. J - Translation, ribosomal structure and biogenesis

MV K - Transcription

Cellular processes and signaling

$\mathrm{T}$ - Signal transduction mechanisms

M - Cell wall/membrane/envelope biogenesis

Z - Cytoskeleton

$\square \mathrm{U}$ - Intracellular trafficking, secretion, and vesicular transport

IIIIIIIIII O - Posttranslational modification, protein turnover, chaperones

\section{Metabolism}

프 C - Energy production and conversion

ㅍㅛㅛ G - Carbohydrate transport and metabolism

E E - Amino acid transport and metabolism

$\mathrm{H}$ - Coenzyme transport and metabolism

I - Lipid transport and metabolism

VIII $\mathrm{P}$ - Inorganic ion transport and metabolism

$\square$ Q - Secondary metabolites biosynthesis, transport and catabolism

F - Nucleotide transport and metabolism

\section{Poorly characterized}

R - General function prediction only

S - Function unknown
} 
workers after the transition to the adult stage. Only hexamerin 70a persists in adult workers (Danty et al. 1998; Cunha et al. 2005). Transcripts of hexamerin 110, 70a, and 70b have been detected in developing ovaries and testes; 110 is highly transcribed in the ovaries of egg-laying queens (Martins et al. 2010). An overexpression of six forms of 110 from the early to middle stages of the pupae head was observed (Zheng et al. 2011). The immunolocalization of hexamerin $70 \mathrm{a}$ revealed a tissue-specific role in developing and maturing ovarioles and testioles (Martins et al. 2011). This observation implies that hexamerin 110 is a storage protein that plays a role in honeybee metamorphosis and in amino acid acquisition in eggs, whereas hexamerins $70 \mathrm{~b}$ and $70 \mathrm{c}$ play roles after emergence and $70 \mathrm{a}$ remains functional in adults.

\subsection{Olfaction-odorant binding and chemosensory proteins}

Olfaction plays crucial role in insect reproduction and in recognition of food odors. However, in highly social species, such as A. mellifera, olfaction is not only used to recognize airborne molecules but to provide thousands of members of a colony with a sensory network (Foret and Maleszka 2006). Insect odorant-binding proteins (Obps), which are small ( 13-20 kDa) proteins that greatly enhance the solubility of hydrophobic odorants, were identified from the chemosensory organs, and some of the Obps are thought to be antenna specific. They can be roughly classified as pheromone binding proteins and general odorant-binding proteins (Briand et al. 2002; Laughlin et al. 2008; Gu et al. 2011; Spinelli et al. 2012). Despite a long-term study, the physiological function of Obps is still not well understood (Zhou 2010).

Expression profiling has revealed that only 9 of 21 Obps in the A. mellifera genome are antenna specific, and the remaining genes are either ubiquitously expressed or are tightly regulated in non-olfactory specialized tissues or during specific developmental stages (Foret and Maleszka 2006). Recently, proteomic studies demonstrated differential protein expression in the antennae of the $A$. mellifera drone, worker, and queen (Fang et al. 2012) as well as the drone and forager (Feng et al. 2011), and different olfactory mechanisms were identified in drones and workers of $A$. mellifera ligustica and Apis cerana cerana (Woltedji et al. 2012). Obp13, 14, 15, and chemosensory protein 3 were identified in the hemolymph of the $A$. mellifera summer worker (Bogaerts et al. 2009), and Obp14 was found in winter worker hemolymph (Erban et al. 2013).

During development, the Obps in the red-eye pupa hemolymph likely arises from Obp13, which is highly expressed in older larvae and throughout the pupal stages; from Obp14 and Obp15, which are found in larvae and are thought disappear after pupation; or from Obp10, which appears in pupae and reaches the highest level in the brain of newly emerged bees before declining in older bees (Foret and Maleszka 2006). We identified two of these Obps, Obp13 (NP_001035314) and Obp14 (NP_001035313), similarly to Zheng et al. (2011) who identified Obp13 and 14 expression during $A$. mellifera pupa head development (Zheng et al. 2011). Thus, our results demonstrated that Obp14 does not disappear after pupation and is a relatively abundant pupal protein.

Small chemosensory proteins (CSPs) are similar to Obps and share some of their characteristics; however, they belong to a distinct evolutionary lineage (Foret et al. 2007). In this study, we identified chemosensory protein 3 precursor (CSP3; NP_001011583 or CAJ01448 with same sequence). Briand et al. (2002) observed that this protein is a brood pheromone carrier in A. mellifera (Briand et al. 2002). Foret et al. (2007) found CSP3 in late larvae but no detectable expression during the initial stages of pupal development (24 h); however, the CSP3 transcripts were again detectable in red-eye pupae, and its level gradually increased until the head became dark. This result suggested that CSP3 plays a role in cuticle maturation and its binding properties are not limited only to brood pheromone recognition but can transport hydrophobic cuticular hydrocarbons. Thus, it was concluded that CSPs are multifunctional, context-dependent proteins involved in diverse cellular processes ranging from embryonic development to chemosensory signal transduction, and some CSPs may function in cuticle synthesis, consistent with their 
evolutionary origins in arthropods (Foret et al. 2007).

The function of Obps and CSPs in hemolymph is not clear; however, due to the facts mentioned above and the binding capacity of these proteins for hydrophobic compounds, it seems possible that they function as transport proteins in the hemolymph.

\subsection{Lipid transport and metabolism (I category)}

Fatty acid-binding proteins (FABPs; NP_001011630) and FABP-like proteins (NP_001011636) are lipid chaperones that facilitate the transport of lipids. FABPs are abundantly expressed 14-15 $\mathrm{kDa}$ proteins that are present across a wide range of both invertebrate and vertebrate species. FABPs bind reversibly to hydrophobic ligands with high affinity, such as saturated and unsaturated long-chain fatty acids and other lipophilic substances, including eicosanoids and retinoids (Furuhashi and Hotamisligil 2008). In addition to being involved in metabolic pathways, FABPs are linked to inflammatory pathways (Makowski and Hotamisligil 2004). Honeybee FABPs are thought to be connected to the insulin/insulin-like signaling network, which is conserved among animals and is central to growth and development (Wolschin et al. 2011). FABPs were found to be continuously highly expressed in honeybee worker larvae but showed decreased expression in adults (Randolt et al. 2008), suggesting age-dependent decreases in the worker hemolymph. FABP (clone 1BH4 in reference Evans and Wheeler (1999)) is notable for its potentially differential expression between castes, as it is expressed in worker but not queen larvae (Evans and Wheeler 1999). More recently, differences in the expression of FABPs have been found in the drone, worker, and queen antennal proteomes (Fang et al. 2012).

Lipophorins are the principal lipoproteins in the insect hemolymph that transport fats and other hydrophobic compounds (Robbs et al. 1985). Apolipophorin III-like (NP_001107670) is a prototypical, exchangeable apolipoprotein found in many insect species that functions in the adult life stage to transport diacylglycerol from the fat body lipid storage depot to flight muscles (Wang et al. 2002).
ApoLp-III is a multifunctional insect protein that can stimulate antimicrobial peptide production in insect hemolymph, enhance phagocytosis in insect blood cells (hemocytes), and may act as a pattern recognition molecule for multiple microbial and parasitic invaders (Whitten et al. 2004). The ApoLpIII transcripts of Africanized honeybees were found to be strongly downregulated after bacterial infection (Lourenco et al. 2009). We identified another lipoprotein, apolipophorins-like (XP_003249876), which was present in a number of isoforms and/or subunits and is also likely restricted to typical insect lipid transport functions.

The key enzymes involved in fatty acid betaoxidation are 3-ketoacyl-CoA thiolase-like (XP_391843), lambda crystalline-like a 3-hydroxyacylCoA dehydrogenase (NP_001129207), medium-chain acyl-CoA dehydrogenase (XP 392111), and enoylCoA hydratase (XP_001123353). Beta-oxidation is typically localized to the mitochondria and/or peroxisomes, and acetyl-CoA, the entry molecule of the citric acid cycle, is generated by breaking down fatty acids (Kunau et al. 1995).

\subsection{Carbohydrate transport and metabolism ( $G$ category)}

$\alpha$-Glucosidase (NP_001035349) contains the $\alpha$-amylase catalytic domain found in maltase and an $\alpha, \alpha$-phosphotrehalase domain (Marchler-Bauer et al. 2013). Therefore, $\alpha$ glucosidase is related to the metabolism of maltose and/or trehalose, which is the main hemolymph sugar in most insects (Thompson 2003).

The chitinase-like protein Idgf4-like (XP_396769; XP_001120887) belongs to the family of imaginal disk growth factors (Idgfs), which are structurally related to chitinases, but an amino acid substitution in their active site abrogates their hydrolase activity. Idgfs are secreted and transported to target tissues via the hemolymph. In Drosophila, in cooperation with insulin, Idgfs stimulate the proliferation, polarization, and motility of imaginal disk cells (Kawamura et al. 1999). Idgf4 is considered a developmental protein in A. mellifera larva ( $\mathrm{Li}$ et al. 2010a, b). 
The beta- $N$-acetylhexosaminidase subunit beta-like ( $\beta$-GlcNAcase; XP_001122538) protein is a chitinolytic enzyme that plays an important role in metamorphosis because it degrades chitin by hydrolyzing $N$-acetylated chitooligosaccharides to $\mathrm{N}$-acetylglucosamine (Nagamatsu et al. 1995). A proteomic analysis identified $\beta$-GlcNAcase as a protein involved in larval to pupal metamorphosis in Bombyx mori (Hou et al. 2010).

The enolase-like (ENO; XP_625056), fructose-biphosphate aldolase-like (FbaB; XP_623342), glyceraldehyde 3-phosphate dehydrogenase (GADPH; XP_393605), phosphoglycerate mutase 2-like (XP_625114), and triosephosphate isomerase (TPI; NP_001090623) enzymes are generally connected to glycolysis pathways, within which most reverse steps constitute gluconeogenesis pathways. However, these enzymes can also play divergent roles. ENOs exhibit tissue-specific isoenzymes that can be expressed by alpha, beta, and gamma genes (Tracy and Hedges 2000). In addition to its essential metabolic function in glycolysis, recent studies have revealed new multifunctional roles for ENO, which include affecting transcriptional regulation (Kim and Dang 2005), functioning as a heat shock protein (Aaronson et al. 1995), and binding to polynucleotides and cytoskeletal proteins (al-Giery and Brewer 1992). ENO has been shown to exist extracellularly (Falabella et al. 2009) and is associated with the Aphidius ervi extracellular fatty acid-binding protein (Falabella et al. 2005). FbaB catalyzes the reversible aldol condensation of dihydroxyacetone phosphate and glyceraldehyde-3-phosphate to fructose-1,6bisphosphate during glycolysis and gluconeogenesis (Marchler-Bauer et al. 2013). Notably, FbaB and ENO have been found to be more abundantly expressed in the hemolymph of immune-challenged Drosophila melanogaster larvae (Vierstraete et al. 2004). GADPH was first identified as a glycolytic dehydrogenase that oxidizes glucose into $\mathrm{CO}_{2}$ and $\mathrm{H}_{2} \mathrm{O}$, producing energy; however, more recent research has shown that GAPDH is a multifunctional protein with a structural role in many fundamental cellular pathways (Kim and Dang 2005; Sirover 2011).
These novel functions include protein binding, induction of apoptosis, maintenance of DNA integrity, tRNA export, transcriptional and posttranscriptional gene regulation, vesicular transport and receptor-mediated cell signaling (Sirover 2011). An extracellular isoform of GADPH was also found to inhibit cell spreading (Yamaji et al. 2005). TPI is not only essential in glycolysis and gluconeogenesis but is also involved in fatty acid biosynthesis and the pentose phosphate shunt (Hollan et al. 1995).

Phosphoglucomutase (PGM1; XP_395366) is essential in both glycogenolysis and the opposite step, glycogenesis. PGM1 catalyzes the bidirectional interconversion of glucose-1phosphate and glucose-6-phosphate (G-6-P) via a glucose-1,6-diphosphate intermediate (Marchler-Bauer et al. 2013). In insects, G-6-P can enter the glycolysis or trehalose synthesis pathway (Meyer-Fernandes et al. 2001) or can be used for chitin synthesis (Muthukrishnan et al. 2012), which is connected to glutamine synthetase (see Section 4.6 below). PGM1 expression has been detected in the hemolymph in all stages in B. mori, although it was found to be weakly expressed relative to other tissues (Staykova 2008).

Hydroxypyruvate isomerase (EFN70011 Camponotus floridanus) interconverts aldoses and ketoses and participates in glyoxylate and dicarboxylate metabolism. Hydroxypyruvate isomerase has also been identified in B. mori hemolymph (Hou et al. 2010). In addition, 6-phosphogluconate dehydrogenase, decarboxylating (XP_625090), and glucose-6-phosphate 1-dehydrogenase (XP_001121185), which both participate in the pentose phosphate pathway and serve as a major source of reducing power and metabolic intermediates for biosynthetic processes (Kruger and von Schaewen 2003), were identified.

\subsection{Energy production and conversion (C category)}

Two dehydrogenases, retinal dehydrogenase 1like (RALDH1; XP_392104) and an aldehyde 
dehydrogenase (XP_623084), contain a region for catalyzing the oxidation of retinal (retinaldehyde) to retinoic acid, which is an important morphogen in growth and development in the chordate/ vertebrate lineage, but with no evidence of function in invertebrates (Luo et al. 2006; Marletaz et al. 2006). Therefore, it is necessary to isolate and characterize these enzymes to prove that RALDH1 or another enzyme function in $A$. mellifera pupa.

Malate dehydrogenases (MDHs; XP_392478 and XP_394487) are key enzymes involved in the biosynthesis of lipids due to their ability to produce NADPH. Recent research indicates that MDH functions go beyond the basic metabolism and address their potential role in cell differentiation and ontogenic development (Danis and Farkas 2009). Insect MDHs are regulated by both $\mathrm{JH}$ and ecdysone during development. In D. melanogaster, MDH activity is low at the beginning of postembryonic development and gradually increases in larva, culminating in the first half of the last larval instar; then, MDH activity decreases during the pupal stage and finally increasing again with age in adults (Farkas and Knopp 1998). An MDH analysis of individuals throughout development in A. mellifera indicated identical MDH isozyme patterns for larvae and adults, while in pupae, the isoenzyme pattern was more complex; an additional pupal-specific expression of a MDH or an epigenetic modification of the isozymes was suggested (Contel et al. 1977).

Arginine kinase (AK; NP_001011603) constitutes part of eight known phosphagen systems, each of which consists of a phosphagen that serves as a reservoir of phosphate-bond energy and a corresponding phosphagen kinase. In general, phosphagen kinase reactions function in temporal ATP buffering, regulating inorganic phosphate levels (which affects glycogenolysis and proton buffering) and intracellular energy transport. AKs are functionally analogous to the more thoroughly studied creatine kinases, which are involved in the only phosphagen system found in vertebrates (Ellington 2001). Expression of AKs was found to be hormonally regulated during $D$. melanogaster development, notably in prepupa by 20-hydroxyecdysone (James and Collier 1990).

Other proteins belonging to the $\mathrm{C}$ category included the electron transfer flavoprotein subunit beta-like (XP_393789), ATP synthase subunits beta (XP_624156) and alpha (XP_392639), v-type proton ATPase subunit B-like (XP_624112), isocitrate dehydrogenase [NADP] (IDH; XP_623673), pyruvate dehydrogenase E1 component subunit beta (NP_001229442), and 4-hydroxybutyrate coenzyme A transferase-like (XP 003696005 Apis florea) proteins. Notably, IDH has been identified as a component of the supramolecular $\mathrm{JH}-$ binding protein complex in Galleria melonella (Zalewska et al. 2011) and is associated with the MDH part of the tricarboxylate cycle in basic metabolism (Danis and Farkas 2009).

\subsection{Amino acid transport and metabolism (E category)}

Spermidine synthase (XP_001120306) synthesizes polyamine spermidine. Polyamines have been implicated in physiological and developmental processes in many organisms, including insects ( $\mathrm{Wu}$ et al. 2010). The high polyamine and spermidine concentrations observed during periods of intravitelline nuclear division, cell formation, and cell proliferation suggest the involvement of polyamines in continued embryonic growth (Callaerts et al. 1992). The involvement of spermidine in metamorphosis has been demonstrated in Tenebrio molitor (Besson et al. 1986).

Glutamine synthetase (GlnS; NP_001164445) is essential in the metabolism of nitrogen as it catalyzes the condensation of glutamate and ammonia to form glutamine. GlnS is also involved in chitin synthesis (see Section 4.4 above) because glutamate is a by-product of chitin synthesis in the epidermis, where glucosaminephosphate isomerase transfers an amino group from glutamine to fructose-6-phosphate to produce glucosamine (which is then acetylated to form $\mathrm{N}$-acetylglucosamine) and glutamate (Yarema et al. 2000). The processing of Lglutamate, which was retrieved from the molting 
fluid by GlnS, was observed in the pupal midgut of Calpodes ethlius (Yarema et al. 2000).

Beta-ureidopropionase-like (BU; XP_392773), also known as $\beta$-alanine synthase, catalyzes the third and final step of reductive pyrimidine degradation (Wasternack 1980). In addition, BU serves as a major endogenous $\beta$-alanine source. The structure of BU has been characterized in D. melanogaster (Lundgren et al. 2008). In insects, $\beta$-alanine is used with dopamine in insect cuticle tanning (sclerotization and pigmentation; Arakane et al. 2009). Therefore, BU may play a crucial role in cuticle sclerotization and the initiation of pigmentation through $\beta$-alanine production during metamorphosis in the honeybee pupa.

Neprilysin 2 (XP 393860) is a member of the M13 peptidase family. The insect M13 peptidases have been found to be associated with metamorphosis, specifically with insect imaginal disks (Zhao et al. 2001; Wilson et al. 2002). Cytosolic nonspecific dipeptidase-like (XP_395851) is a metalloexopeptidase that contains a region for M20 cytosolic nonspecific dipeptidases, including anserinase and serum carnosinase (Marchler-Bauer et al. 2013). Finally, the last member identified in the $\mathrm{E}$ category was kynurenine-oxoglutarate transaminase 3 (EGI61832 Acromyrmex echinatior).

\subsection{Post-translational modification, protein turnover, chaperones ( $O$ category)}

Numerous protein groups in the $\mathrm{O}$ category were heat shock proteins (HSPs) and heat shock cognates (HSCs). HSPs are generally grouped into several different families, including the chaperonin family (HSP110, 100, 90, 70, 60, and 40) and the small heat shock (sHSP)/ $\alpha$-crystallin (AC) proteins (Liang and MacRae 1997; Ranford et al. 2000). We identified HSP90 (NP_001153536) and endoplasmin-like (XP_395614) with an HSP90 region (Marchler-Bauer et al. 2013), HSP60 (XP_392899), a 10-kDa sHSP (XP_624910), and an AC (XP_392405); however, HSP70 was not identified. Three HSCs, an HSC3 (NP_001153524), an HSC4 (NP_001153522), and an HSC5 (NP_001153520), were recognized. HSPs70 and HSCs70 (HSC3-5) are similar chaperones that assist in distinct cellular functions (Goldfarb et al. 2006). HSP expression levels were originally found to increase under exposure to heat shock or other stressors. These proteins are synthesized constitutively and mediate many cellular processes by influencing and supporting a higher order of protein structure (Liang and MacRae 1997; Bukau and Horwich 1998). In addition, they are potent immunogens, and their secreted forms can interact with a variety of cell types to activate key cellular activities, such as the synthesis of cytokines and adhesion proteins (Ranford et al. 2000). HSP90 has essential roles in eukaryotic cells in the folding and activation of a range of proteins involved in cell cycle regulation, steroid hormone responsiveness, and signal transduction (Prodromou et al. 1997). HSPs10 are known to promote substrates bound to HSP60 (Ranford et al. 2000) and the cooperation of HSP60 and HSP70 can mediate the native folding of proteins in an ATP-dependent manner (Liang and MacRae 1997; Bukau and Horwich 1998). ACs are known to be major proteins found in the eye lens, but they are also detected in many other cell types (Horwitz 2009). In addition, we identified the epsilon subunit of the $\mathrm{t}$-complex protein (XP_003400274 Bombus terrestris), which belongs to the chaperonin family for which cytoskeletal proteins, tubulins, and actins appear to be the primary substrates (Coghlin et al. 2006).

Glutathione-S-transferases (GSTs; XP_624662; NP_001153742; XP_003689632 A. florea), peroxiredoxins (XP_003249289; NP_001164444) and thioredoxin reductase (NP_001171497) are enzymes connected to the antioxidative defense system (AOS) that eliminates reactive oxygen species (ROS) generated as by-products of aerobic metabolism (Corona and Robinson 2006). XP_624662 and NP_001153742 GSTs were sigma class GSTs with a high affinity for the products of lipid peroxidation (Singh et al. 2001). The strong spots observed for XP_624662 indicate that this protein plays a major role in the pupa hemolymph during metamorphosis. Because XP_624662 in earlier studies was also identified in honeybee hemolymph in summer (Bogaerts et al. 2009) and winter adults (Erban et al. 2013), worker and queen larvae (Li et al. 2010b) venom (Peiren et al. 2008), royal jelly ( $\mathrm{Li}$ et al. 2008), and developing 
hypopharyngeal glands (Feng et al. 2009; Li et al. 2010a), it is apparent that this enzyme is ubiquitous throughout the entire life cycle of the honeybee.

1(2)37Cc-like (XP_391959) is a member of the prohibitin family that has been found to be involved in cuticle formation and catecholamine metabolism and is required for larval metabolism and the progression of the larva to the pupal stage in Drosophila (Eveleth and Marsh 1986). Additionally, 14-3-3 protein epsilon (14-3-3 $\varepsilon$ ) (XP_392479; NP 001091764 B. mori) and 14-3-3 protein zeta-like (14-3-3द; Leonardo) (XP_003692803 A. florea) are both essential during development for regulating the cell cycle in Drosophila (Su et al. 2001; Acevedo et al. 2007). It has been demonstrated that $14-3-3 \varepsilon$ serves as a central modulator of the activity of the transcription factor FoxO in Drosophila in vivo, thus regulating growth, apoptosis and longevity (Nielsen et al. 2008). Lysozomal aspartic protease (XP_392857) is similar to cathepsin D (NP_001037351 B. mori, identity $64 \%$ ) in that it has been found to be critically involved in programmed cell death during B. mori metamorphosis (Gui et al. 2006). $1(2) 37 \mathrm{Cc}, 14-3-3 \varepsilon, 14-3-3 \zeta$ and cathepsin D have all been identified as the important proteins involved in honeybee larval development (Li et al. 2010b); thus, developmental function of these proteins is obvious also in pupa.

Furthermore, we identified disulfideisomerases (XP_623831; XP_623282), which catalyze thiol-disulfide exchange reactions and exhibit chaperone activity (Hatahet and Ruddock 2009), and peptidyl-prolyl cis-trans isomerases (NP_001229473; XP_624498; XP_397224), which interconvert the $c i s$ and trans isomers of peptide bonds with the amino acid proline and can act as molecular timers in many biological and pathological processes ( $\mathrm{Lu}$ et al. 2007). Additionally, we found components of the 26S (XP_623053) and the 20S proteasomes (XP 394993; XP 393468; XP_003697298) (Coux et al. 1996), which are responsible for the degradation of proteins (Coux et al. 1996); the t-complex protein 1 subunit epsilon (XP_393315), which belongs to the TCP-1 chaperonin family
(Marchler-Bauer et al. 2013); and stress-inducedphosphoprotein 1-like (XP_003486756 Bombus impatiens).

\subsection{Inorganic ion transport and metabolism ( $P$ category)}

$\mathrm{Cu}^{2+} / \mathrm{Zn}^{2+}$ superoxide dismutase (SOD1; NP_001171498) and catalase (NP_001171540) are the primary components of the AOS that are necessary for the maintenance of redox homeostasis. SOD1 and catalase act in tandem and eliminate ROS. SOD converts superoxide anion radicals to $\mathrm{H}_{2} \mathrm{O}_{2}$ and catalase breaks down $\mathrm{H}_{2} \mathrm{O}_{2}$ into water and oxygen, which eliminates the production of highly reactive hydroxyl free radicals (Orr and Sohal 1994).

Ferritins are characterized by high capacities for iron storage and are composed of two types of 24 small polypeptide chains. One subunit type (XP_624044) is responsible for the ferroxidase activity of these subunits and is essential for the incorporation of iron into the ferritin shell. The second ferritin subunit (XP_624076) typifies these subunits. Most insect ferritins are secreted, which is in contrast to the predominantly cytosolic vertebrate ferritins and plant ferritins, which are found in plastids (Dunkov and Georgieva 2006). Voltage-dependent anion-selective channels (XP_623725) are a type of porin ion channel involved in the regulation of the metabolite flow across the mitochondria (Komarov et al. 2004).

\subsection{Secondary metabolites biosynthesis, transport and catabolism ( $Q$ category)}

Short-chain dehydrogenase/reductase (SDR; NP_001011620), which was identified in multiple isoforms, exhibits great functional diversity. NP_001011620 is identical to NCBI record $\mathrm{AAP} 45005$, which has been reported to be a target of the ecdysone response during $A$. mellifera caste development (Guidugli et al. 2004). This SDR (clone 52A9 in Evans and Wheeler (1999)) was previously found to be worker-specific (Evans and Wheeler 1999). A crucial developmental role of SDRs in ecdysteroidogenesis has been reported in 
several insect species (Niwa et al. 2010). The enzyme 3-hydroxyacyl-CoA dehydrogenase type2-like (HADH2) (XP_001120471) was later identified as 17-hydroxysteroid dehydrogenase 10 (HSD10) (Marchler-Bauer et al. 2013). HSD10/HADH2 is a member of the SDR family and shows a broad spectrum of enzymatic activities towards steroids and other compounds, such as prostaglandins, retinoids and fatty acid derivatives (Shafqat et al. 2003).

Fumarylacetoacetase (XP_624590) is involved in the tyrosine catabolism pathway (MarchlerBauer et al. 2013). Sorbitol dehydrogenase-like isoform 2 (SDH; XP_392401) is the second enzyme in the polyol pathway and catalyzes the conversion of sorbitol to fructose (MarchlerBauer et al. 2013).

\subsection{General function prediction only ( $R$ category)}

Juvenile hormone esterase (JHE; NP_001011563/ XP_392274) is identical to NCBI protein records AAU 81605 (in Mackert et al. (2008)) and BAC54130 (in Kamikouchi et al. (2004)). JHEs constitute the major metabolic route for $\mathrm{JH}$ production, which controls this stage of insect development. Thus, JHEs function as regulators of honeybee castes, behavior, and development (Kamikouchi et al. 2004; Mackert et al. 2008).

Aldose reductase-like (AR; XP 624353) is associated with SDH (see above XP 392401), as it is the first enzyme in the polyol pathway and catalyzes the reduction of glucose to sorbitol (Marchler-Bauer et al. 2013). Alcohol dehydrogenase [NADP+] A-like (XP_624401), similar to AR, belongs to the aldo/ keto reductase protein family, which has a primary purpose to reduce aldehydes and ketones to primary and secondary alcohols (Marchler-Bauer et al. 2013).

Cytosol aminopeptidase-like (XP_003249720) is a member of the M17 family that includes leucyl aminopeptidase (Marchler-Bauer et al. 2013). The phosphotriesterase-related protein-like (XP 395159) protein is a member of the amidohydrolase superfamily and has a sequence that is highly similar to phosphotriesterase but shows little or no esterase activity (Wang et al. 2011), while phosphatidylethanolaminebinding protein homolog F40A3.3-like (XP_392060) belongs to the phosphatidylethanolamine-binding protein family, which has members that have different substrates and oligomerization states (Marchler-Bauer et al. 2013). The last members of the $\mathrm{R}$ category were arylsulfatase J-like (XP_624454) and hypothetical protein TcasGA2_TC004196 (EFA12567 Tribolium castaneum), which has a region for pepsin-like aspartate proteases from retroviruses (Marchler-Bauer et al. 2013).

\subsection{Other categories}

Seven members were classified as belonging to the multiple function category due to presenting more than one assigned function: calumenin (XP_624357; categories T and U); slit homolog 2 protein (XP_003249857) (categories W and T); hypothetical protein LOC409786 (XP_393280) (categories $\mathrm{T}$ and $\mathrm{Z}$ ); trans-1,2-dihydrobenzene1,2-diol dehydrogenase-like (XP_623497; categories $\mathrm{G}$ and $\mathrm{Q}$ ); uncharacterized oxidoreductase yrbE (XP_624408; categories C and Q); nacetylneuraminate lyase (XP_001120250; categories $\mathrm{E}$ and $\mathrm{M}$ ), which assists in the metabolism of sialic acids (Maru et al. 1998); and trans-1,2dihydrobenzene-1,2-diol dehydrogenase-like (XP_623497; categories C and Q), which is connected to the synthesis of catechol, an important function in the construction of the insect skeleton (Kramer et al. 2001).

In the translation, ribosomal structure and biogenesis $(\mathrm{J})$ category, we identified ribonuclease UK114 (XP_003251902), eukaryotic initiation factor 4A (XP_623285), hypothetical protein LOC551211 (XP_623682), tyrosyl-tRNA synthetase (XP_397348), elongation factor 1-alpha (NP_001014993), N(2),N(2)-dimethylguanosine tRNA methyltransferase (XP_003249791), and a 40S ribosomal protein, SA (XP_393965).

The proteins assigned to the function unknown (S) category include transferrin 1 (NP_001011572), which is the best-studied insect transferrin. This multifunctional glycoprotein functions to reduce oxidative stress and enhance the duration of infections, in addition to its canonical role of iron delivery (as reviewed by Geiser and Winzerling (2012)). Transferrin expression in A. mellifera has been reported to be controlled by ecdysteroids (do 
Nascimento et al. 2004). Other proteins in the $\mathrm{S}$ category were an ester hydrolase C11orf54 homo$\log$ (XP_394859), endochitinase-like (XP_003402985 B. terrestris), hypothetical protein (ADD51172), hypothetical protein LOC727503 (XP_001123213), hypothetical protein LOC412149 (XP 395613), hypothetical protein LOC726722 (XP_001122443), hypothetical protein LOC100578640 (XP_003250458), hypothetical protein LOC100746991 (XP_392060 B. impatiens), hypothetical protein LOC 100647123 (XP_003401909 B. terrestris) and hypothetical protein LOC725960 (XP_001121746).

Six proteins were categorized as belonging to the cytoskeleton $(\mathrm{Z})$ category. Actin-related protein 1 (NP 001172074), actin, clone 205-like (XP_003251465), tubulin beta-1 chain (XP_392313), and tubulin beta-3 chain-like (XP 394469) are cytoskeletal proteins that are likely found in hemolymph cells. Actin is detectable in hemolymph hemocytes (Matova and Anderson 2010), and tubulin was also previously identified in honeybee hemolymph (Chan et al. 2006). Profilin (NP_001011626) and a cofilin/ actin-depolymerizing factor homolog (XP_001120072) are proteins that bind to actin and affect the structure of the cytoskeleton (Marchler-Bauer et al. 2013).

Other proteins with one or a few members in a category were also identified. Slit homolog 2 protein-like (XP_001120937), which is required for normal neural development (Holmes et al. 1998), belongs to the signal transduction mechanisms (T) category. Annexin B9-like (XP_395944) belongs in the intracellular trafficking, secretion, and vesicular transport (U) category and is a $\mathrm{Ca}^{2+}$-dependent phospholipid-binding protein that demonstrates down-regulated expression in cells that are destined to undergo apoptosis but not in those that survive pupal metamorphosis in B. mori (Kaneko et al. 2006). A pyridoxal kinase-like (XP_625042) protein, assigned to the coenzyme transport and metabolism $(\mathrm{H})$ category, plays a key role in the synthesis of the active coenzyme pyridoxal-5'-phosphate (MarchlerBauer et al. 2013). Nucleoside diphosphate kinase (XP_393351), which catalyzes the phosphorylation of nucleoside diphosphates to form triphos- phates (Schneider et al. 2001), and deoxyribosephosphate aldolase-like (XP_624372), which catalyzes the aldol reaction between two aldehydes (Marchler-Bauer et al. 2013), both belong to the nucleotide transport and metabolism (F) category. A member of the transcription $(\mathrm{K})$ category was pterin-4-alpha-carbinolamine dehydratase (XP 395077). Finally, in the cell wall $/ \mathrm{mem}$ brane/envelope biogenesis (M) category, we identified an apolipoprotein D-like (XP_623787), which belongs to the lipocalin family and functions as transporters for small hydrophobic molecules, such as lipids, steroid hormones, bilins, and retinoids (Marchler-Bauer et al. 2013).

\section{CONCLUSIONS}

We have generated a 2DE protein profile of $A$. mellifera worker red-eye pupa hemolymph. A total of 129 different proteins were identified and organized into orthologous groups. One of the key accomplishments of our study was that we were able to detect the distribution of four hexamerins, which are the major storage proteins in A. mellifera, within the 2DE map. Thus, future studies that involve examining the consumption of hexamerin 110, 70a, 70b, and 70c during development may benefit from our results. All of the identified proteins will be useful as markers for future comparative physiological and developmental studies. The generated 2DE map can also be used to investigate $V$. destructor physiology and host-parasite interactions because the pupal hemolymph serves as the sole food source for this major honeybee pest.

\section{ACKNOWLEDGMENTS}

This study was supported by grants from the Grant Agency of the Ministry of Agriculture of the Czech Republic (http://eagri.cz/public/web/mze/), grant nos.: QI111A119 and QJ1310085; the Ministry of Education, Youth and Sports of the Czech Republic (http://www.msmt.cz/), grant no: OC10016 (COST FA0803 action-Prevention of Honeybee Colony Losses (COLOSS)). The authors would like to thank the anonymous reviewers and editor for their valuable comments and suggestions that have improved the manuscript. 
Analyse protéomique par gel bidimensionnel de l'hémolymphe des pupes (stade 'yeux rouges') de l'ouvrière d'abeille, Apis mellifera

Pupe / abeille / hémolymphe / métamorphose / protéome / hexamérine

Proteomanalyse der Hämolymphe rotäugiger Arbeiterinnenpuppen mittels zweidimensionaler Gele

\section{Honigbienenpuppe / Hämolymphe / Metamorphose / Proteom / Hexamerin}

\section{REFERENCES}

Aaronson, R.M., Graven, K.K., Tucci, M., McDonald, R.J., Farber, H.W. (1995) Non-neuronal enolase is an endothelial hypoxic stress protein. J. Biol. Chem. 270, 27752-27757

Acevedo, S.F., Tsigkari, K.K., Grammenoudi, S., Skoulakis, E.M.C. (2007) In vivo functional specificity and homeostasis of Drosophila 14-3-3 proteins. Genetics 177, 239-253

Al-Giery, A.G., Brewer, J.M. (1992) Characterization of the interaction of yeast enolase with polynucleotides. Biochim. Biophys. Acta 1159, 134-140

Arakane, Y., Lomakin, J., Beeman, R.W., Muthukrishnan, S., Gehrke, S.H., Kanost, M.R., Kramer, K.J. (2009) Molecular and functional analyses of amino acid decarboxylases involved in cuticle tanning in Tribolium castaneum. J. Biol. Chem. 284, 16584-16594

Barchuk, A.R., Bitondi, M.M.G., Simoes, Z.L.P. (2002) Effects of juvenile hormone and ecdysone on the timing of vitellogenin appearance in hemolymph of queen and worker pupae of Apis mellifera. J. Insect Sci. 2, 1

Besson, M.T., Delbecque, J.P., Mathelin, J., Boisson, A.M., Delachambre, J. (1986) Epidermal polyamine levels related to cell cycle events during the metamorphosis of Tenebrio molitor L. (insecta, coleoptera): effect of juvenoid application. Comp. Biochem. Physiol B 83, 589-593

Bitondi, M.M.G., Nascimento, A.M., Cunha, A.D., Guidugli, K.R., Nunes, F.M.F., Simoes, Z.L.P. (2006) Characterization and expression of the Hex 110 gene encoding a glutamine-rich hexamerin in the honey bee Apis mellifera. Arch. Insect Biochem. Physiol 63, 57-72

Bogaerts, A., Baggerman, G., Vierstraete, E., Schoofs, L., Verleyen, P. (2009) The hemolymph proteome of the honeybee: gel-based or gel-free? Proteomics 9, 3201-3208
Briand, L., Swasdipan, N., Nespoulous, C., Bezirard, V., Blon, F., Huet, J.C., Ebert, P., Penollet, J.C. (2002) Characterization of a chemosensory protein (ASP3c) from honeybee (Apis mellifera L.) as a brood pheromone carrier. Eur. J. Biochem. 269, 4586-4596

Bukau, B., Horwich, A.L. (1998) The Hsp70 and Hsp60 chaperone machines. Cell 92, 351-366

Burmester, T. (2002) Origin and evolution of arthropod hemocyanins and related proteins. J. Comp. Physiol. B 172, 95-107

Burmester, T., Hankeln, T. (2007) The respiratory proteins of insects. J. Insect Physiol. 53, 285-294

Burmester, T., Scheller, K. (1999) Ligands and receptors: common theme in insect storage protein transport. Naturwissenschaften 86, 468-474

Burmester, T., Massey Jr., H.C., Zakharkin, S.O., Benes, H. (1998) The evolution of hexamerins and the phylogeny of insects. J. Mol. Evol. 47, 93-108

Callaerts, P., Geuns, J., De Loof, A. (1992) Polyamine changes during early development of Drosophila melanogaster. J. Insect Physiol. 38, 751-758

Cardoen, D., Ernst, U.R., Van Vaerenbergh, M., Boerjan, B., de Graaf, D.C., Wenseleers, T., Schoofs, L., Verleyen, P. (2011) Differential proteomics in dequeened honeybee colonies reveals lower viral load in hemolymph of fertile worker bees. PLoS One 6, e20043

Chan, Q.W.T., Foster, L.J. (2008) Changes in protein expression during honey bee larval development. Genome Biol. 9, R156

Chan, Q.W.T., Howes, C.G., Foster, L.J. (2006) Quantitative comparison of caste differences in honeybee hemolymph. Mol. Cell. Proteomics 5, 2252-2262

Coghlin, C., Carpenter, B., Dundas, S.R., Lawrie, L.C., Telfer, C., Murray, G.I. (2006) Characterization and over-expression of chaperonin t-complex proteins in colorectal cancer. J. Pathol. 210, 351-357

Contel, E.P.B., Mestriner, M.A., Martins, E. (1977) Genetic control and development expression of malate dehydrogenase in Apis mellifera. Biochem. Genet. 15, 859-876

Corona, M., Robinson, G.E. (2006) Genes of the antioxidant system of the honey bee: annotation and phylogeny. Insect Mol. Biol. 15, 687-701

Coux, O., Tanaka, K., Goldberg, A.L. (1996) Structure and functions of the $20 \mathrm{~S}$ and $26 \mathrm{~S}$ proteasomes. Annu. Rev. Biochem. 65, 801-847

Cunha, A.D., Nascimento, A.M., Guidugli, K.R., Simoes, Z.L.P., Bitondi, M.M.G. (2005) Molecular cloning and expression of a hexamerin cDNA from the honey bee Apis mellifera. J Insect Physiol 51, 1135-1147

Danis, P., Farkas, R. (2009) Hormone-dependent and hormone-independent control of metabolic and developmental functions of malate dehydrogenase - review. Endocr. Regul. 43, 39-52

Danty, E., Arnold, G., Burmester, T., Huet, J.C., Huet, D., Pernollet, J.C., Masson, C. (1998) Identification 
and developmental profiles of hexamerins in antenna and hemolymph of the honeybee Apis mellifera. Insect Biochem. Mol. Biol. 28, 387-397

Do Nascimento, A.M., Cuvillier-Hot, V., Barchuk, A.R., Simoes, Z.L.P., Hartfelder, K. (2004) Honey bee (Apis mellifera) transferrin-gene structure and the role of ecdysteroids in the developmental regulation of its expression. Insect Biochem. Mol. Biol. 34, 415-424

Duay, P., De Jong, D., Engels, W. (2003) Weight loss in drone pupae (Apis mellifera) multiply infested by Varroa destructor mites. Apidologie 34, 61-65

Dunkov, B., Georgieva, T. (2006) Insect iron binding proteins: insights from the genomes. Insect Biochem. Mol. Biol. 36, 300-309

Ellington, W.R. (2001) Evolution and physiological roles of phosphagen systems. Annu. Rev. Physiol. 63, 289-325

Erban, T., Jedelsky, P.L., Titera, D. (2013) Two-dimensional proteomic analysis of honeybee, Apis mellifera, winter worker hemolymph. Apidologie 44, 404-418

Evans, J.D., Wheeler, D.E. (1999) Differential gene expression between developing queens and workers in the honey bee Apis mellifera. Proc. Natl. Acad. Sci. USA 96, 5575-5580

Eveleth, D.D., Marsh, J.L. (1986) Sequence and expression of the $\mathrm{Cc}$ gene, a member of the DOPA decarboxylase gene cluster of Drosophila: possible translational regulation. Nucleic Acids Res. 14, 6169-6183

Falabella, P., Perugino, G., Caccialupi, P., Riviello, L., Varricchio, P., Tranfaglia, A., Rossi, M., Malva, C., Graziani, F., Moracci, M., Pennacchio, F. (2005) A novel fatty acid binding protein produced by teratocytes of the aphid parasitoid Aphidius ervi. Insect Mol. Biol. 14, 195-205

Falabella, P., Riviello, L., De Stradis, M.L., Stigliano, C., Varricchio, P., Grimaldi, A., de Eguileor, M., Graziani, F., Gigliotti, S., Pennacchio, F. (2009) Aphidius ervi teratocytes release an extracellular enolase. Insect Biochem. Mol. Biol. 39, 801-813

Fang, Y., Song, F.F., Zhang, L., Aleku, D.W., Han, B., Feng, M., Li, J.K. (2012) Differential antennal proteome comparison of adult honeybee drone, worker and queen (Apis mellifera L.). J Proteomics 75, 756-773

Farkas, R., Knopp, J. (1998) Genetic and hormonal control of cytosolic malate dehydrogenase activity in Drosophila melanogaster. Gen. Physiol. Biophys. 17, 37-50

Feng, M., Fang, Y., Li, J.K. (2009) Proteomic analysis of honeybee worker (Apis mellifera) hypopharyngeal gland development. BMC Genomics 10, 645

Feng, M., Song, F.F., Aleku, D.W., Han, B., Fang, Y., Li, J.K. (2011) Antennal proteome comparison of sexually mature drone and forager honeybees. J. Proteome Res. 10, 3246-3260

Foret, S., Maleszka, R. (2006) Function and evolution of a gene family encoding odorant binding-like proteins in a social insect, the honey bee (Apis mellifera). Genome Res. 16, 1404-1413
Foret, S., Wanner, K.W., Maleszka, R. (2007) Chemosensory proteins in the honey bee: insights from the annotated genome, comparative analyses and expressional profiling. Insect Biochem. Mol. Biol. 37, 19-28

Furuhashi, M., Hotamisligil, G.S. (2008) Fatty acid-binding proteins: role in metabolic diseases and potential as drug targets. Nat. Rev. Drug Discov. 7, 489-503

Geiser, D.L., Winzerling, J.J. (2012) Insect transferrins: multifunctional proteins. Biochim. Biophys. Acta 1820, 437-451

Goldfarb, S.B., Kashlan, O.B., Watkins, J.N., Suaud, L., Yan, W., Kleyman, T.R., Rubenstein, R.C. (2006) Differential effects of Hsc70 and Hsp70 on the intracellular trafficking and functional expression of epithelial sodium channels. Proc. Natl. Acad. Sci. USA 103, 5817-5822

Gu, S.H., Wang, S.P., Zhang, X.Y., Wu, K.M., Guo, Y.Y., Zhou, J.J., Zhang, Y.J. (2011) Identification and tissue distribution of odorant binding protein genes in the lucerne plant bug Adelphocoris lineolatus (Goeze). Insect Biochem. Mol. Biol. 41, 254-263

Gui, Z.Z., Lee, K.S., Kim, B.Y., Choi, Y.S., Wei, Y.D., Choo, Y.M., Kang, P.D., Yoon, H.J., Kim, I., Je, Y.H., Seo, S.J., Lee, S.M., Guo, X., Sohn, H.D., Jin, B.R. (2006) Functional role of aspartic proteinase cathepsin $\mathrm{D}$ in insect metamorphosis. BMC Dev. Biol. 6, 49

Guidugli, K.R., Hepperle, C., Hartfelder, K. (2004) A member of the short-chain dehydrogenase/reductase (SDR) superfamily is a target of the ecdysone response in honey bee (Apis mellifera) caste development. Apidologie 35, 37-47

Gullan, P.J., Cranston, P.S. (2005) The insects: an outline of entomology, 3rd edn. Blackwell, USA

Hatahet, F., Ruddock, L.W. (2009) Protein disulfide isomerase: a critical evaluation of its function in disulfide bond formation. Antioxid. Redox Signal. 11, 2807-2850

Hollan, S., Dey, I., Szollar, L., Horanyi, M., Magocsi, M., Harsanyi, V., Farkas, T. (1995) Erythrocyte lipids in triose-phosphate isomerase deficiency. Proc. Natl. Acad. Sci. USA 92, 268-271

Holmes, G.P., Negus, K., Burridge, L., Raman, S., Algar, E., Yamada, T., Little, M.H. (1998) Distinct but overlapping expression patterns of two vertebrate slit homologs implies functional roles in CNS development and organogenesis. Mech. Dev. 79, 57-72

Honeybee Genome Sequencing Consortium (2006) Insights into social insects from the genome of the honeybee Apis mellifera. Nature 443, 931-949

Horwitz, J. (2009) Alpha crystallin: the quest for a homogeneous quaternary structure. Exp. Eye Res. 88, 190-194

Hou, Y., Zou, Y., Wang, F., Gong, J., Zhong, X., Xia, Q., Zhao, P. (2010) Comparative analysis of proteome maps of silkworm hemolymph during different developmental stages. Proteome Sci. 8, 45

Hrassnigg, N., Leonhard, B., Crailsheim, K. (2003) Free amino acids in the haemolymph of honey bee 
queens (Apis mellifera L.). Amino Acids 24, 205212

James, J.M., Collier, G.E. (1990) Hormonally regulated expression of arginine kinase in Drosophila melanogaster. Roux's Arch. Dev. Biol. 198, 474478

Kamikouchi, A., Morioka, M., Kubo, T. (2004) Identification of honeybee antennal proteins/genes expressed in a sex- and/or caste selective manner. Zoolog. Sci. 21, 53-62

Kaneko, Y., Takaki, K., Iwami, M., Sakurai, S. (2006) Developmental profile of annexin IX and its possible role in programmed cell death of the Bombyx mori anterior silk gland. Zoolog. Sci. 23, $533-542$

Kawamura, K., Shibata, T., Saget, O., Peel, D., Bryant, P.J. (1999) A new family of growth factors produced by the fat body and active on Drosophila imaginal disc cells. Development 126, 211-219

Kim, J.W., Dang, C.V. (2005) Multifaceted roles of glycolytic enzymes. Trends Biochem. Sci. 30, 142-150

Komarov, A.G., Graham, B.H., Craigen, W.J., Colombini, M. (2004) The physiological properties of a novel family of VDAC-like proteins from Drosophila melanogaster. Biophys. J. 86, 152-162

Kramer, K.J., Kanost, M.R., Hopkins, T.L., Jiang, H.B., Zhu, Y.C., Xu, R.D., Kerwin, J.L., Turecek, F. (2001) Oxidative conjugation of catechols with proteins in insect skeletal systems. Tetrahedron 57, 385-392

Kruger, N.J., von Schaewen, A. (2003) The oxidative pentose phosphate pathway: structure and organisation. Curr. Opin. Plant Biol. 6, 236-246

Kunau, W.H., Dommes, V., Schulz, H. (1995) betaoxidation of fatty acids in mitochondria, peroxisomes, and bacteria: a century of continued progress. Prog. Lipid Res. 34, 267-342

Laughlin, J.D., Ha, T.S., Jones, D.N.M., Smith, D.P. (2008) Activation of pheromone-sensitive neurons is mediated by conformational activation of pheromone-binding protein. Cell 133, 12551265

Lavine, M.D., Strand, M.R. (2002) Insect hemocytes and their role in immunity. Insect Biochem. Mol. Biol. 32, 1295-1309

Leta, M.A., Gilbert, C., Morse, R.A. (1996) Levels of hemolymph sugars and body glycogen of honeybees (Apis mellifera $\mathrm{L}$ ) from colonies preparing to swarm. J. Insect Physiol. 42, 239-245

Levy, F., Bulet, P., Ehret-Sabatier, L. (2004) Proteomic analysis of the systemic immune response of Drosophila. Mol. Cell. Proteomics 3, 156-166

Li, J.K., Feng, M., Zhang, L., Zhang, Z.H., Pan, Y.H. (2008) Proteomics analysis of major royal jelly protein changes under different storage conditions. J. Proteome. Res. 7, 3339-3353

Li, J.K., Feng, M., Begna, D., Fang, Y., Zheng, A.J. (2010a) Proteome comparison of hypopharyngeal gland development between Italian and royal jelly producing worker honeybees (Apis mellifera L.). J. Proteome Res. 9, 6578-6594

Li, J.K., Wu, J., Begna Rundassa, D., Song, F.F., Zheng, A.J., Fang, Y. (2010b) Differential protein expression in honeybee (Apis mellifera L.) larvae: underlying caste differentiation. PLoS One 5, e13455

Liang, P., MacRae, T.H. (1997) Molecular chaperones and the cytoskeleton. J. Cell Sci. 110, 1431-1440

Lourenco, A.P., Martins, J.R., Bitondi, M.M.G., Simoes, Z.L.P. (2009) Trade-off between immune stimulation and expression of storage protein genes. Arch. Insect Biochem. Physiol. 71, 70-87

Lu, K.P., Finn, G., Lee, T.H., Nicholson, L.K. (2007) Prolyl cis-trans isomerization as a molecular timer. Nat. Chem. Biol. 3, 619-629

Lundgren, S., Lohkamp, B., Andersen, B., Piskur, J., Dobritzsch, D. (2008) The crystal structure of betaalanine synthase from Drosophila melanogaster reveals a homooctameric helical turn-like assembly. J. Mol. Biol. 377, 1544-1559

Luo, T., Sakai, Y., Wagner, E., Drager, U.C. (2006) Retinoids, eye development, and maturation of visual function. J. Neurobiol. 66, 677-686

Mackert, A., Do Nascimento, A.M., Bitondi, M.M.G., Hartfelder, K., Simoes, Z.L.P. (2008) Identification of a juvenile hormone esterase-like gene in the honey bee, Apis mellifera L. - expression analysis and functional assays. Comp. Biochem. Physiol. B 150, 33-44

Makowski, L., Hotamisligil, G.S. (2004) Fatty acid binding proteins - the evolutionary crossroads of inflammatory and metabolic responses. J. Nutr. 134, 2464S-2468S

Marchler-Bauer, A., Zheng, C.J., Chitsaz, F., Derbyshire, M.K., Geer, L.Y., Geer, R.C., Gonzales, N.R., Gwadz, M., Hurwitz, D.I., Lanczycki, C.J., Lu, F., Lu, S.N., Marchler, G.H., Song, J.S., Thanki, N., Yamashita, R.A., Zhang, D.C., Bryant, S.H. (2013) CDD: conserved domains and protein three-dimensional structure. Nucleic Acids Res. 41, D348-D352

Marletaz, F., Holland, L.Z., Laudet, V., Schubert, M. (2006) Retinoic acid signaling and the evolution of chordates. Int. J. Biol. Sci. 2, 38-47

Martins, J.R., Nunes, F.M.F., Simoes, Z.L.P., Bitondi, M.M.G. (2008) A honeybee storage protein gene, hex $70 \mathrm{a}$, expressed in developing gonads and nutritionally regulated in adult fat body. J. Insect Physiol. 54, 867-877

Martins, J.R., Nunes, F.M.F., Cristino, A.S., Simoes, Z.L.P., Bitondi, M.M.G. (2010) The four hexamerin genes in the honey bee: structure, molecular evolution and function deduced from expression patterns in queens, workers and drones. BMC Mol. Biol. 11, 23

Martins, J.R., Anhezini, L., Dallacqua, R.P., Simoes, Z.L.P., Bitondi, M.M.G. (2011) A honey bee hexamerin, HEX 70a, is likely to play an 
intranuclear role in developing and mature ovarioles and testioles. PLoS One 6, e29006

Maru, I., Ohnishi, J., Ohta, Y., Tsukada, Y. (1998) Simple and large-scale production of $N$-acetylneuraminic acid from $N$-acetyl-D-glucosamine and pyruvate using $N$-acyl-Dglucosamine 2-epimerase and $N$-acetylneuraminate lyase. Carbohydr. Res. 306, 575-578

Masova, A., Sanda, M., Jiracek, J., Selicharova, I. (2010) Changes in the proteomes of the hemocytes and fat bodies of the flesh fly Sarcophaga bullata larvae after infection by Escherichia coli. Proteome Sci. 8, 1

Matova, N., Anderson, K.V. (2010) Drosophila Rel proteins are central regulators of a robust, multiorgan immune network. J. Cell Sci. 123, 627-633

Meyer-Fernandes, J.R., Clark, C.P., Gondim, K.C., Wells, M.A. (2001) Fat body fructose-2,6-bisphosphate content and phosphorylase activity correlate with changes in hemolymph glucose concentration during fasting and re-feeding in larval Manduca sexta. Insect Biochem. Mol. Biol. 31, 165-170

Michelette, E.R.F., Soares, A.E.E. (1993) Characterization of preimaginal developmental stages in Africanized honey bee workers (Apis mellifera L). Apidologie 24, 431-440

Muthukrishnan, S., Merzendorfer, H., Arakane, Y., Kramer, K.J. (2012) Chitin metabolism in insects. In: Gilbert, L.I. (ed.) Insect molecular biology and biochemistry, pp. 193-235. Academic, New York

Nagamatsu, Y., Yanagisawa, I., Kimoto, M., Okamoto, E., Koga, D. (1995) Purification of a chitooligosaccharidolytic beta- $N$-acetylglucosaminidase from Bombyx mori larvae during metamorphosis and the nucleotide sequence of its cDNA. Biosci. Biotechnol. Biochem. 59, 219-225

Nielsen, M.D., Luo, X., Biteau, B., Syverson, K., Jasper, H. (2008) 14-3-3 epsilon antagonizes FoxO to control growth, apoptosis and longevity in Drosophila. Aging Cell 7, 688-699

Niwa, R., Namiki, T., Ito, K., Shimada-Niwa, Y., Kiuchi, M., Kawaoka, S., Kayukawa, T., Banno, Y., Fujimoto, Y., Shigenobu, S., Kobayashi, S., Shimada, T., Katsuma, S., Shinoda, T. (2010) Non-molting glossy/ shroud encodes a short-chain dehydrogenase/reductase that functions in the 'Black Box' of the ecdysteroid biosynthesis pathway. Development 137, 19911999

Orr, W.C., Sohal, R.S. (1994) Extension of life-span by overexpression of superoxide dismutase and catalase in Drosophila melanogaster. Science 263, 1128-1130

Peiren, N., de Graaf, D.C., Vanrobaeys, F., Danneels, E.L., Devreese, B., Van Beeumen, J., Jacobs, F.J. (2008) Proteomic analysis of the honey bee worker venom gland focusing on the mechanisms of protection against tissue damage. Toxicon 52, $72-83$

Piulachs, M.D., Guidugli, K.R., Barchuk, A.R., Cruz, J., Simoes, Z.L.P., Belles, X. (2003) The vitellogenin of the honey bee, Apis mellifera: structural analysis of the
cDNA and expression studies. Insect Biochem. Mol. Biol. 33, 459-465

Prodromou, C., Roe, S.M., O'Brien, R., Ladbury, J.E., Piper, P.W., Pearl, L.H. (1997) Identification and structural characterization of the ATP/ADPbinding site in the Hsp90 molecular chaperone. Cell 90, 65-75

Randolt, K., Gimple, O., Geissendorfer, J., Reinders, J., Prusko, C., Mueller, M.J., Albert, S., Tautz, J., Beier, H. (2008) Immune-related proteins induced in the hemolymph after aseptic and septic injury differ in honey bee worker larvae and adults. Arch. Insect Biochem. Physiol. 69, 155-167

Ranford, J.C., Coates, A.R., Henderson, B. (2000) Chaperonins are cell-signalling proteins: the unfolding biology of molecular chaperones. Expert Rev. Mol. Med. 2, 1-17

Rembold, H., Kremer, J.P., Ulrich, G.M. (1980) Characterization of postembryonic developmental stages of the female castes of the honey bee, Apis mellifera L. Apidologie 11, 29-38

Robbs, S.L., Ryan, R.O., Schmidt, J.O., Keim, P.S., Law, J.H. (1985) Lipophorin of the larval honeybee, Apis mellifera L. J. Lipid Res. 26, 241-247

Schneider, B., Babolat, M., Xu, Y.W., Janin, J., Veron, M., Deville-Bonne, D. (2001) Mechanism of phosphoryl transfer by nucleoside diphosphate kinase $\mathrm{pH}$ dependence and role of the active site Lys16 and Tyr56 residues. Eur. J. Biochem. 268, 1964-1971

Shafqat, N., Marschall, H.U., Filling, C., Nordling, E., Wu, X.Q., Bjork, L., Thyberg, J., Martensson, E., Salim, S., Jornvall, H., Oppermann, U. (2003) Expanded substrate screenings of human and Drosophila type 1017 betahydroxysteroid dehydrogenases (HSDs) reveal multiple specificities in bile acid and steroid hormone metabolism: characterization of multifunctional 3 alpha/7 alpha/ 7 beta/17 beta/20 beta/21-HSD. Biochem. J. 376, 49-60

Singh, S.P., Coronella, J.A., Benes, H., Cochrane, B.J., Zimniak, P. (2001) Catalytic function of Drosophila melanogaster glutathione S-transferase DmGSTS1-1 (GST-2) in conjugation of lipid peroxidation end products. Eur. J. Biochem. 268, 2912-2923

Sirover, M.A. (2011) On the functional diversity of glyceraldehyde-3-phosphate dehydrogenase: biochemical mechanisms and regulatory control. Biochim. Biophys. Acta 1810, 741-751

Spinelli, S., Lagarde, A., Iovinella, I., Legrand, P., Tegoni, M., Pelosi, P., Cambillau, C. (2012) Crystal structure of Apis mellifera OBP14, a C-minus odorant-binding protein, and its complexes with odorant molecules. Insect Biochem. Mol. Biol. 42, 41-50

Staykova, T. (2008) Genetically-determined polymorphism of nonspecific esterases and phosphoglucomutase in eight introduced breeds of the silkworm, Bombyx mori, raised in Bulgaria. J. Insect Sci. 8, 18

Su, T.T., Parry, D.H., Donahoe, B., Chien, C.T., O'Farrell, P.H., Purdy, A. (2001) Cell cycle roles for two 14-3-3 proteins during Drosophila development. J. Cell Sci. 114, 3445-3454 
Thompson, S.N. (2003) Trehalose - the insect 'blood' sugar. Adv. Insect Physiol. 31, 205-285

Tracy, M.R., Hedges, S.B. (2000) Evolutionary history of the enolase gene family. Gene 259, 129-138

Vierstraete, E., Verleyen, P., Baggerman, G., D'Hertog, W., Van den Bergh, G., Arckens, L., De Loof, A., Schoofs, L. (2004) A proteomic approach for the analysis of instantly released wound and immune proteins in Drosophila melanogaster hemolymph. Proc. Natl. Acad. Sci. USA 101, 470-475

Wang, J., Sykes, B.D., Ryan, R.O. (2002) Structural basis for the conformational adaptability of apolipophorin III, a helix-bundle exchangeable apolipoprotein. Proc. Natl. Acad. Sci. USA 99, 1188-1193

Wang, X., Gao, K., Wu, P., Qin, G., Liu, T., Guo, X. (2011) Molecular cloning of a phosphotriesterase-related protein gene of silkworm and its expression analysis in the silkworm infected with Bombyx mori cytoplasmic polyhedrosis virus. Agric. Sci. 2, 406-412

Wasternack, C. (1980) Degradation of pyrimidines and pyrimidine analogs - pathways and mutual influences. Pharmacol. Ther. 8, 629-651

Whitten, M.M.A., Tew, I.F., Lee, B.L., Ratcliffe, N.A. (2004) A novel role for an insect apolipoprotein (apolipophorin III) in beta-1,3-glucan pattern recognition and cellular encapsulation reactions. J. Immunol. 172, 2177-2185

Wilson, C.L., Shirras, A.D., Isaac, R.E. (2002) Extracellular peptidases of imaginal discs of Drosophila melanogaster. Peptides 23, 2007-2014

Wolschin, F., Mutti, N.S., Amdam, G.V. (2011) Insulin receptor substrate influences female caste development in honeybees. Biol. Lett. 7, 112-115
Woltedji, D., Song, F.F., Zhang, L., Gala, A., Han, B., Feng, M., Fang, Y., Li, J.K. (2012) Western honeybee drones and workers (Apis mellifera ligustica) have different olfactory mechanisms than eastern honeybees (Apis cerana cerana). J. Proteome Res. 11, 4526-4540

Wu, S.B., Wang, M.Q., Zhang, G.A. (2010) Effects of putrescine on diapause induction and intensity, and post-diapause development of Helicoverpa armigera. Entomol. Exp. Appl. 136, 199-205

Yamaji, R., Chatani, E., Harada, N., Sugimoto, K., Inui, H., Nakano, Y. (2005) Glyceraldehyde-3phosphate dehydrogenase in the extracellular space inhibits cell spreading. Biochim. Biophys. Acta 1726, 261-271

Yarema, C., McLean, H., Caveney, S. (2000) Lglutamate retrieved with the moulting fluid is processed by a glutamine synthetase in the pupal midgut of Calpodes ethlius. J. Insect Physiol. 46, 1497-1507

Zalewska, M., Ozyhar, A., Kochman, M. (2011) Identification of specific interaction of juvenile hormone binding protein with isocitrate dehydrogenase. Acta Biochim. Pol. 58, 119-124

Zhao, X., Mita, K., Shimada, T., Okano, K., Quan, G.X., Kanke, E., Kawasaki, H. (2001) Isolation and expression of an ecdysteroid-inducible neutral endopeptidase 24.11-like gene in wing discs of Bombyx mori. Insect Biochem Mol. Biol. 31, 1213-1219

Zheng, A.J., Li, J.K., Begna, D., Fang, Y., Feng, M., Song, F.F. (2011) Proteomic analysis of honeybee (Apis mellifera L.) pupae head development. PLoS One 6, e20428

Zhou, J.J. (2010) Odorant-binding proteins in insects. Vitam. Horm. 83, 241-272 